\title{
A Retrospective Clinicopathological Study of Osteosarcoma Patients with Metachronous Metastatic Relapse
}

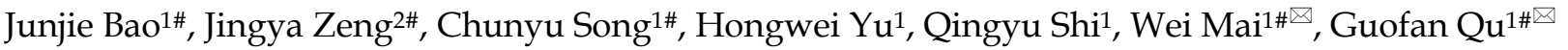 \\ 1. Department of Orthopedic Surgery, Harbin Medical University Cancer Hospital, Harbin, China \\ 2. Department of Clinical Laboratory, Harbin Medical University Cancer Hospital, Harbin, China. \\ \#Contribute equally \\ $\triangle$ Corresponding authors: Guofan Qu, Wei Mai. Mailing address: Department of Orthopedic Surgery, Harbin Medical University Cancer Hospital, 150 Haping \\ Road, Nangang District, Harbin, China. Phone: +86 451 85718203; E-mail: guofanqu@126.com. OICRD: https://orcid.org/0000-0002-7102-155X \\ (c) Ivyspring International Publisher. This is an open access article distributed under the terms of the Creative Commons Attribution (CC BY-NC) license \\ (https://creativecommons.org/licenses/by-nc/4.0/). See http://ivyspring.com/terms for full terms and conditions.
}

Received: 2018.10.27; Accepted: 2019.04.15; Published: 2019.06.02

\begin{abstract}
Purpose: Although osteosarcoma patients receive a standardized treatment, metachronous metastatic relapse still impairs the overall survival (OS). This study aimed to explore the clinicopathological features and prognostic factors of osteosarcoma patients with metachronous metastatic relapse.

Patients and methods: We retrospectively analyzed 59 patients, between January 1st, 2004 and December 31st, 2013. Employed Chi-square test to recognize the differences in clinicopathological characteristics between early and late metastatic patients, and the differences between shorter and longer survival patients. Used the Kaplan-Meier method to evaluate the survival data, cox step proportional hazard test to analyze the prognostic factors associated with OS.

Results: We found that early metastatic patients were prominently correlated with the male, tumor size $\geq 8$ $\mathrm{cm}$, histological grade G2, Enneking stages II, anatomic location of the distal femur, pathological of conventional types, and elevated alkaline phosphatase (ALP) level at diagnosis, $(p<0.05)$. In parallel, the shorter survival patients were primarily linked to tumor size $\geq 8 \mathrm{~cm}$, histological grade G2, Enneking stages II, early metastasis, multiple pulmonary metastases, lack of curative treatment after metastasis, increased level of ALP at diagnosis and LDH after metastasis, $(\mathrm{p}<0.05)$. The univariate analyses of the prognostic factors showed that patients who had these clinicopathological characteristics, such as male, tumor size $\geq 8 \mathrm{~cm}$, Enneking stage IIB, multiple pulmonary metastases, lack of curative treatment after metastasis, the elevated ALP at diagnosis, elevated ALP and LDH after metastasis, had a worse OS in osteosarcoma patient with metachronous metastatic relapse, $(p<0.05)$. The multivariate analyses showed that tumor size, type of metastasis and ALP level at diagnosis were independent factors for OS in osteosarcoma patient with metachronous metastatic relapse $(p<0.05)$.

Conclusion: These results indicated that osteosarcoma patients with metachronous metastatic relapse have special features which might be utilized to effectively predict the likelihood of early metastatic relapse and the prognosis.
\end{abstract}

Key words: osteosarcoma, metastatic relapse, clinicopathological characteristics, prognosis.

\section{Introduction}

Osteosarcoma is the most common primary malignant bone tumor which seriously affecting children and adolescents in particular [1]. Currently, the primary treatment of osteosarcoma includes neoadjuvant and adjuvant poly-chemotherapy, and radical resection of the tumor between the chemotherapy cycles. This multi-modal treatment strategy raises the overall survival (OS) from 10-20\% up to $65-70 \%$, but metastasis remains the biggest obstacle to clinical prognosis [2]. The osteosarcoma originates from mesenchymal cells such as immature bone and bone-like tissue, which contributes to high invasiveness and early metastasis [3]. Dramatic differences were observed in the prognosis of 
osteosarcoma patients with or without distant metastasis [4]. Patients with synchronous distant metastasis often lose the opportunity for standardized treatment lead to the worse prognosis. Some patients develop metastases during treatment, and they have a poor prognosis which is similar with synchronous distant metastasis. However, patients with metachronous metastatic relapse frequently exists metastasis after standardized treatment especially during the follow-up, which is the main reason for clinical treatment failed [5-7]. It is an important step to summarize the characteristics of patients with metachronous metastatic relapse to find more pieces of evidence and clinicopathological characteristics for predicting the outcome of patients after receiving standard treatment. Furthermore, some future inspection or treatment might be taken to postpone the occurrence of metastasis and detect metastatic relapse in the early stage through effective follow-up. Until now, there are few relevant studies related to the clinicopathological characteristics of osteosarcoma patients with metachronous metastatic relapse. Hence, it is essential to conduct a comprehensive study including all possible prognostic factors of these patients.

This study was to relatively and comprehensively analyze and compare clinicopathological characteristics and prognostic factors among relatively 59 patients with metachronous metastatic relapse. We verified the features of patients who are more likely to progress to early metastatic relapse after receiving standard treatment and established the corresponding theoretical basis for seeking potential mechanisms and reduce the rate of metachronous metastatic relapse to further improve the prognosis of osteosarcoma patients.

\section{Patients and Methods}

\section{Inclusion and exclusion criteria}

The study was employed as a retrospective analysis of children and adolescent osteosarcoma patients with metachronous metastatic relapse. At the Orthopedic Surgery Department of Harbin Medical University Cancer Hospital, China, 198 patients had been histologically confirmed osteosarcoma between January 1st, 2004 and December 31st, 2013. The study design was approved by the ethics review board from Harbin Medical University Cancer Hospital. All patients signed informed consent.

Among these patients who met the following criteria were included in the study.

(1) Patients underwent a complete physical examination, imaging examinations, and blood tests at preoperatively.

(2) All patients in the study had received radical surgery (R0, an absence of a residual tumor both macroscopically and microscopically) either amputation or limb salvage surgery.

(3) Metastatic tumors occurred at least three months after patients had been completed the standard treatment. If a biopsy was feasible for the suspicious distant metastatic lesion, after biopsy, patients were diagnosed with metastatic osteosarcoma. If positions of the suspicious lesion were unfeasible for a biopsy, it was necessary to exclude the possibility of the primary tumor according to the independent diagnosis which was made by three or more experts including a musculoskeletal radiologist, musculoskeletal oncologist, and chest oncologist.

(4) All selected patients had not been received pre-operative radiotherapy.

(5) Clinicopathological data and follow-up data were available.

(6) Based on the median time to metastasis (16 months), the patients were separated into the early metastatic (EM) group and late metastatic (LM) group. The EM group included patients who developed metastatic relapse within 3 to 16 months after standard treatment. The LM group included patients their time to metastasis was longer than 16 months.

(7) Based on the length of survival after metastasis, the patients were separated into the shorter survival (SS) group and the longer survival (LS) group. The SS group refers to the length of survival after metastasis was shorter than 12 months. The LS group refers to the length of survival after metastasis was longer than 12 months.

Among these patients who met the following criteria were excluded in the study.

(1) There was a metastatic tumor at the time of diagnosis or during the treatment.

(2) Unable to perform a biopsy or inconsistent diagnosis by the experts.

(3) There were incomplete clinicopathological data or follow-up data.

\section{Treatment protocols}

Patients who met the above criteria had received a standardized treatment, including preoperative neoadjuvant chemotherapy for 3 cycles (3 weeks per cycle), and radical surgery and postoperative chemotherapy for additional 8 cycles (G1 patients only underwent surgery). Neoadjuvant chemotherapy protocol consisted of cisplatin (100 $\left.\mathrm{mg} / \mathrm{m}^{2} \mathrm{D} 1\right)$ and doxorubicin $\left(60-80 \mathrm{mg} / \mathrm{m}^{2}\right.$ for 3 days). Postoperative chemotherapy protocol consisted 
of cisplatin $\left(100 \mathrm{mg} / \mathrm{m}^{2} \mathrm{D} 1\right)$ and doxorubicin $(60-80$ $\mathrm{mg} / \mathrm{m}^{2}$ for 3 days) with or without ifosfamide (8-10 $\mathrm{mg} / \mathrm{m}^{2}$ for 5 days). Treatments followed by metastasis included previous chemotherapy protocol, second-line chemotherapy protocol, surgery, radiotherapy, and clinical trial, but the treatment regimens were not uniform.

\section{Data collection}

Data on basic patient characteristics (gender and age), clinicopathological features (duration of symptoms, tumor diameter, histological grade, site of primary tumor, Enneking stage, pathological fracture, anatomic location, pathological types, surgical methods, type of metastasis, and treatment after metastasis), laboratory parameters (serum alkaline phosphatase ALP and lactate dehydrogenase LDH ), imaging examinations (X-Ray, CT, MRI, bone scanning), and treatment information were collected from the medical records by trained investigators.

\section{Follow-up}

The postoperative follow-up at least included:

(1) Physical examination, imaging of primary site and chest and laboratory tests every 3 months for the first 2 years after initial treatment at the orthopedic clinic, then every 4 months for the third year and every 6 months for the fourth and fifth year, and yearly thereafter.

(2) Patients' survival was calculated from initial treatment to death or the last follow-up date (31st Dec 2017).

(3) All data were anonymized and de-identified.

\section{Statistics}

The Chi-square test was used to analyze correlations between classified variables, including the different group of patients and clinicopathological data. The Kaplan-Meier method was used to evaluate the survival data. The cox step proportional hazard test was used to analyze the prognostic factors associated with overall survival. The two-sided $\mathrm{P}$ $<0.05$ was considered to be statistically significant. All data analysis was processed using SPSS 19.0.

\section{Results}

\section{Overall cohort characteristics}

Based on the designed criteria, this retrospective cohort consisted of 59 patients of osteosarcoma patients with metachronous metastatic relapse, including 37 patients $(62.7 \%)$ were categorized as EM group, 22 patients (37.3\%) as LM group, 35 patients $(59.3 \%)$ as SS group and 24 patients $(40.7 \%)$ as LS group. Lung was the main metastatic organ (51/59). There were 16 cases of solitary pulmonary metastases and 35 cases of multiple pulmonary metastases. Other metastatic organs included bone (10/59) and liver $(8 / 59)$. Median metastatic time of the patients was 16 (3-72) months. The median age was 15 (7-29) years, and the male/female ratio was 1.19:1.

\section{Clinical symptoms and laboratory test}

Arthralgia was observed in most patients $(84.7 \%)$, tumor mass was $76.3 \%$, claudication was $37.3 \%$, and the pathological fracture was $11.9 \%$ at the time of diagnosis. Other common symptoms included general malaise $(40.7 \%)$, fever $(20.3 \%)$, weight loss $(15.3 \%)$ and anemia (13.6\%). Patients with elevated alkaline phosphatase (ALP) and lactic dehydrogenase (LDH) at diagnosis accounted for $66.1 \%$ and $16.9 \%$, respectively.

\section{Tumor features}

Most tumors were located nearby the knee joint $(81.4 \%)$. The median tumor diameter was 10.2 $(2.3-17.5) \mathrm{cm}$. Majority of the tumors were the histological grade G2 (93.2\%), were Enneking stage II (93.2\%).

\section{Overall survival}

By the end of the follow-up period, there were 43 cases of patient deaths. Overall, the 1-, 2-, and 3-year event-free survival rates were $79.7 \%(47 / 59), 28.8 \%$ $(17 / 59)$ and $23.7 \%(14 / 59)$, respectively. The 2-, 3-, and 4-year survival rates were $69.5 \%(41 / 59), 40.7 \%$ $(24 / 59)$, and $30.5 \%$ (18/59), respectively. Median overall survival (OS) was 31 (19-110) months, median OS of groups EM and LM were 24 (19-46) months and 83 (32-110) months.

\section{Comparison clinicopathological characteristics between early- and late-metastatic group}

We used the Chi-square test to compare clinicopathological characteristics between the early-and late-metastatic group of osteosarcoma patients with metachronous metastatic relapse. Early metastatic group patients were more likely to be male $(p=0.034)$, tumor size $\geq 8 \mathrm{~cm} \quad(p<0.001)$, higher histological grade $(p=0.016)$, higher Enneking stages $(p=0.004)$, anatomic location of distal femur $(p=0.001)$, pathological of conventional types $(\mathrm{p}=0.002)$, and elevated alkaline phosphatase (ALP) level at diagnosis $(p<0.001)$. There is no statistical significance between these indicators, age $(p=0.763)$, the duration of symptoms (arthralgia, intermittent claudication, weight loss, anemia, etc. $p=0.114$ ), site of primary tumor $(p=0.211)$, pathologic fracture $(p=0.702)$, surgical methods $(p=0.188)$, LDH level at diagnosis $(p=0.294)($ Table 1$)$. 
Table 1. The differences in clinicopathological characteristics between EM group and LM group.

\begin{tabular}{|c|c|c|c|}
\hline Variables & EM group (37 cases) & LM group (22 cases) & $\mathrm{P}$ \\
\hline Gender & & & 0.034 \\
\hline male & $24(64.9 \%)$ & $8(36.4 \%)$ & \\
\hline female & $13(35.1 \%)$ & $14(63.6 \%)$ & \\
\hline Age (years) & & & 0.763 \\
\hline$<15$ & $17(45.9 \%)$ & $11(50.0 \%)$ & \\
\hline$\geq 15$ & $20(54.1 \%)$ & $11(50.0 \%)$ & \\
\hline Duration of Symptoms & & & 0.114 \\
\hline$\geq 3$ months & $8(21.6 \%)$ & $9(40.9 \%)$ & \\
\hline$<3$ months & $29(78.4 \%)$ & $13(59.1 \%)$ & \\
\hline Size & & & 0.000 \\
\hline$\geq 8 \mathrm{~cm}$ & $26(70.3 \%)$ & $4(18.2 \%)$ & \\
\hline$<8 \mathrm{~cm}$ & $11(29.7 \%)$ & $18(81.8 \%)$ & \\
\hline Histological grade & & & 0.016 \\
\hline G1 & $0(0.0 \%)$ & $4(18.2 \%)$ & \\
\hline G2 & $37(100.0 \%)$ & $18(81.8 \%)$ & \\
\hline Site of primary tumor & & & 0.211 \\
\hline $\mathrm{T} 1$ & $14(37.8 \%)$ & $12(54.5 \%)$ & \\
\hline $\mathrm{T} 2$ & $23(62.2 \%)$ & $10(45.5 \%)$ & \\
\hline Enneking stage & & & 0.004 \\
\hline I & $0(0.0 \%)$ & $4(18.2 \%)$ & \\
\hline IIA & $14(37.8 \%)$ & $12(54.5 \%)$ & \\
\hline IIB & $23(62.2 \%)$ & $6(27.3 \%)$ & \\
\hline Pathologic fracture & & & 0.702 \\
\hline Yes & $5(13.5 \%)$ & $2(9.1 \%)$ & \\
\hline No & $32(86.5 \%)$ & $20(90.9 \%)$ & \\
\hline Anatomic location & & & 0.001 \\
\hline Distal femur & $23(62.2 \%)$ & $4(18.2 \%)$ & \\
\hline Proximal tibia & $10(27.0 \%)$ & $8(36.4 \%)$ & \\
\hline Others & $4(10.8 \%)$ & $10(45.4 \%)$ & \\
\hline Pathological types & & & 0.002 \\
\hline Conventional & $37(100.0 \%)$ & $16(72.7 \%)$ & \\
\hline Non-conventional & $0(0.0 \%)$ & $6(27.3 \%)$ & \\
\hline Surgical methods & & & 0.188 \\
\hline Amputation & $20(54.1 \%)$ & $8(36.4 \%)$ & \\
\hline Limb salvage & $17(45.9 \%)$ & $14(63.6 \%)$ & \\
\hline ALP level at diagnosis & & & 0.000 \\
\hline Elevation & $31(83.8 \%)$ & $8(36.4 \%)$ & \\
\hline
\end{tabular}

\begin{tabular}{llll}
\hline Variables & EM group (37 cases) & LM group (22 cases) & P \\
\hline Normal & $6(16.2 \%)$ & $14(63.6 \%)$ & \\
LDH level at diagnosis & & & 0.294 \\
Elevation & $8(21.6 \%)$ & $2(9.1 \%)$ & \\
Normal & $29(78.4 \%)$ & $20(90.9 \%)$ &
\end{tabular}

Abbreviations: EM, early metastasis; LM, late metastasis.

\section{Comparison clinicopathological characteristics between short- and long- survival group.}

We used the Chi-square test to compare clinicopathological characteristics between the short-and long-survival group of osteosarcoma patients with metachronous metastatic relapse. Short survival group patients were more likely to be tumor size $\geq 8 \mathrm{~cm} \quad(\mathrm{p}<0.001)$, higher histological grade $(p=0.012)$, higher Enneking stages $(p=0.007)$, early metastasis $(p<0.001)$, multiple pulmonary metastasis $(p=0.001)$, lack of curative treatment $(p=0.001)$, elevated ALP level at diagnosis $(p<0.001)$ and elevated LDH level after metastasis $(p=0.006)$. There is no statistical significance between these indicators, gender $(p=0.109)$, age $(p=0.072)$, the duration of symptoms $(p=0.222)$, site of primary tumor $(p=0.196)$, pathologic fracture $(p=0.689)$, anatomic location $(p=0.545)$, pathological types $(p=0.212)$, surgical methods $(p=0.072), \mathrm{LDH}$ level at diagnosis $(p=0.177)$, and ALP level after metastasis $(\mathrm{p}=0.064)$ (Table 2$)$.

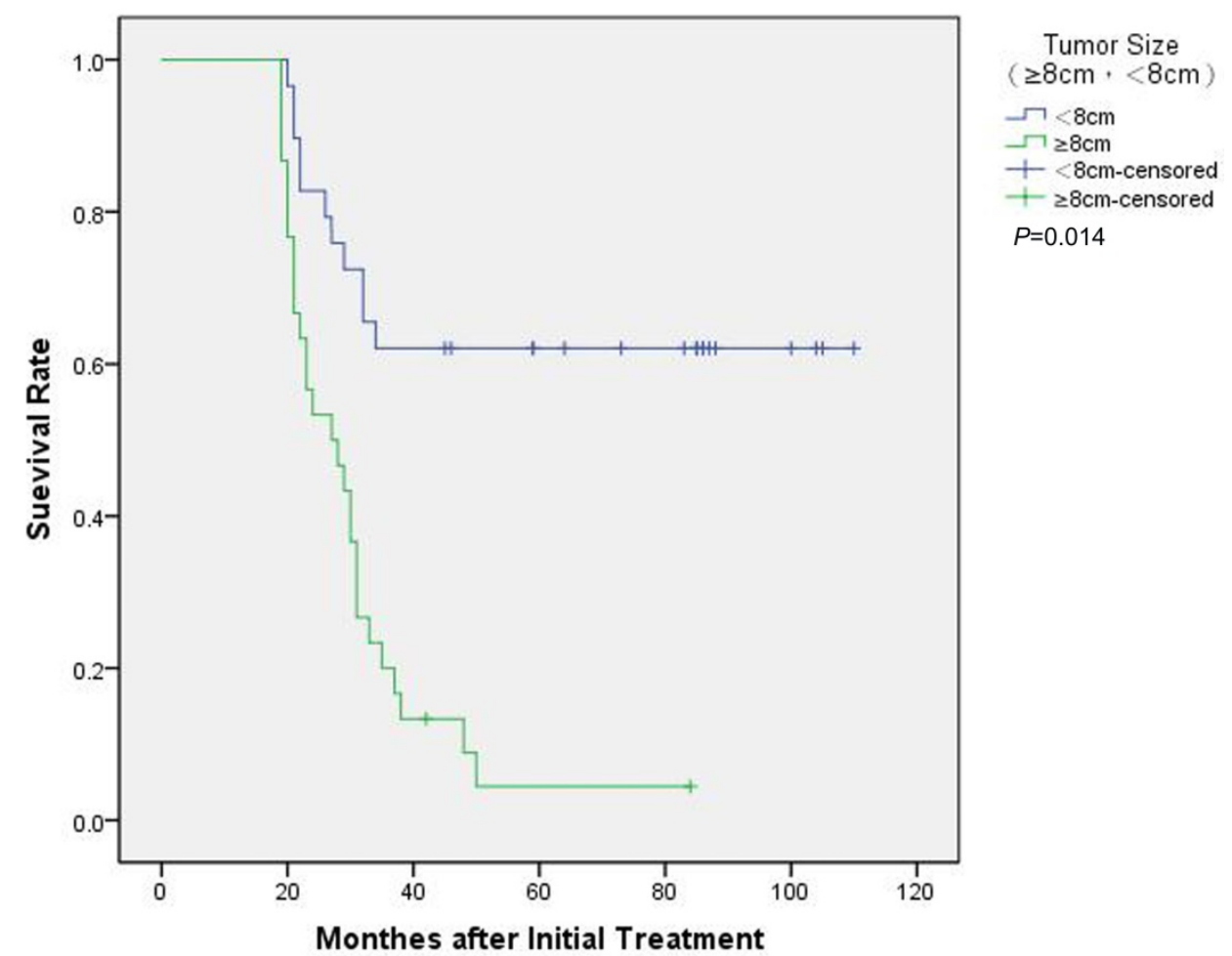

Figure 1. Kaplan-Meier survival curves of 59 metachronous metastatic osteosarcoma patients were stratified by tumor size. Significant differences in survival rate were observed between patients with $\geq 8 \mathrm{~cm}$ and $<8 \mathrm{~cm}$. 


\section{Prognostic factors}

We used the Kaplan-Meier method to evaluate the survival data, cox step proportional hazard test to analyze the prognostic factors associated with OS of patients with metachronous metastatic relapse. The univariate analysis findings revealed that the following factors negatively affecting OS: male, tumor size $\geq 8 \mathrm{~cm}$, Enneking stage IIB, type of metastasis, lack of curative treatment after metastasis, the elevated level of ALP at diagnosis, ALP and LDH level after metastasis $(p<0.05)$. The multivariate analysis showed that the following factors were independent factors for OS: tumor size ( $\geq 8 \mathrm{~cm}$ vs. $<8 \mathrm{~cm}$, HR $3.491,95 \% \mathrm{CI}$ [1.282-9.510], $p=0.014$ ) (Figure 1), type of metastasis (solitary pulmonary vs multiple pulmonary or other organs, HR 0.269, 95\% CI [0.091-0.799], p=0.018) (Figure 2) and ALP level at diagnosis (HR 8.719, 95\% CI [3.082-24.671], p<0.001) (Figure 3) (Table 3).

Table 2. The differences in clinicopathological characteristics between SS group and LS group.

\begin{tabular}{|c|c|c|c|}
\hline Variables & SS group (35 cases) & LS group (24 cases) & $\mathrm{P}$ \\
\hline Gender & & & 0.109 \\
\hline male & $22(62.9 \%)$ & $10(41.7 \%)$ & \\
\hline female & $13(37.1 \%)$ & $14(58.3 \%)$ & \\
\hline Age (years) & & & 0.072 \\
\hline$<15$ & $20(57.1 \%)$ & $8(33.3 \%)$ & \\
\hline$\geq 15$ & $15(42.9 \%)$ & $16(66.7 \%)$ & \\
\hline $\begin{array}{l}\text { Duration of } \\
\text { symptoms }\end{array}$ & & & 0.222 \\
\hline$\geq 3$ months & $8(22.9 \%)$ & $9(37.5 \%)$ & \\
\hline$<3$ months & $27(77.1 \%)$ & $15(62.5 \%)$ & \\
\hline \multicolumn{4}{|l|}{ Size } \\
\hline$\geq 8 \mathrm{~cm}$ & $25(71.4 \%)$ & $5(20.8 \%)$ & 0.000 \\
\hline$<8 \mathrm{~cm}$ & $10(28.6 \%)$ & $19(79.2 \%)$ & \\
\hline Histological grade & & & 0.012 \\
\hline G1 & $0(0.0 \%)$ & $4(16.7 \%)$ & \\
\hline G2 & $35(100.0 \%)$ & $20(83.3 \%)$ & \\
\hline $\begin{array}{l}\text { Site of primary } \\
\text { tumor }\end{array}$ & & & 0.196 \\
\hline $\mathrm{T} 1$ & $13(37.1 \%)$ & $13(54.2 \%)$ & \\
\hline $\mathrm{T} 2$ & $22(62.9 \%)$ & $11(45.8 \%)$ & \\
\hline Enneking stage & & & 0.007 \\
\hline I & $0(0.0 \%)$ & $4(16.7 \%)$ & \\
\hline IIA & $13(37.1 \%)$ & $13(54.2 \%)$ & \\
\hline IIB & $22(62.9 \%)$ & $7(29.1 \%)$ & \\
\hline Pathologic fracture & & & 0.689 \\
\hline Yes & $5(14.3 \%)$ & $2(8.3 \%)$ & \\
\hline No & $30(85.7 \%)$ & $22(92.7 \%)$ & \\
\hline Anatomic location & & & 0.545 \\
\hline Distal femur & $18(51.4 \%)$ & $9(37.5 \%)$ & \\
\hline Proximal tibia & $10(28.6 \%)$ & $8(33.3 \%)$ & \\
\hline Others & $7(20.0 \%)$ & $7(29.2 \%)$ & \\
\hline Pathological types & & & 0.212 \\
\hline Conventional & $33(94.3 \%)$ & $20(83.3 \%)$ & \\
\hline Non-conventional & $2(5.7 \%)$ & $4(16.7 \%)$ & \\
\hline Surgical methods & & & 0.072 \\
\hline Amputation & $20(57.1 \%)$ & $8(33.3 \%)$ & \\
\hline Limb salvage & $15(42.9 \%)$ & $16(66.7 \%)$ & \\
\hline Stage of metastasis & & & 0.000 \\
\hline Early & $30(85.7 \%)$ & $7(29.2 \%)$ & \\
\hline Late & $5(14.3 \%)$ & $17(70.8 \%)$ & \\
\hline Type of metastasis & & & 0.001 \\
\hline Solitary pulmonary & $4(11.4 \%)$ & $11(45.8 \%)$ & \\
\hline Multiple pulmonary & $28(80.0 \%)$ & $8(33.4 \%)$ & \\
\hline Other organs & $3(8.6 \%)$ & $5(20.8 \%)$ & \\
\hline
\end{tabular}

\begin{tabular}{llll}
\hline Variables & SS group (35 cases) & LS group (24 cases) & $\mathrm{P}$ \\
\hline $\begin{array}{l}\text { Treatment after } \\
\text { metastasis } \\
\text { curative }\end{array}$ & $14(40.0 \%)$ & $20(83.3 \%)$ & 0.001 \\
$\begin{array}{l}\text { Palliative or no } \\
\text { treatment }\end{array}$ & $21(60.0 \%)$ & $4(16.7 \%)$ & \\
$\begin{array}{l}\text { ALP level at } \\
\text { diagnosis }\end{array}$ & & & 0.000 \\
$\begin{array}{l}\text { Elevation } \\
\text { Normal }\end{array}$ & $31(88.6 \%)$ & $8(33.3 \%)$ & \\
$\begin{array}{l}\text { LDH level at } \\
\text { diagnosis }\end{array}$ & $4(11.4 \%)$ & $16(66.7 \%)$ & 0.177 \\
$\begin{array}{l}\text { Elevation } \\
\text { Normal }\end{array}$ & $8(32.4 \%)$ & & \\
$\begin{array}{l}\text { ALP level after } \\
\text { metastasis }\end{array}$ & $27(67.6 \%)$ & $22(81.7 \%)$ & \\
$\begin{array}{l}\text { Elevation } \\
\text { Normal }\end{array}$ & $27(67.6 \%)$ & $13(54.2 \%)$ & 0.064 \\
$\begin{array}{l}\text { LDH level after } \\
\text { metastasis }\end{array}$ & $8(32.4 \%)$ & $11(45.8 \%)$ & \\
$\begin{array}{l}\text { Elevation } \\
\text { Normal }\end{array}$ & $19(54.3 \%)$ & $4(16.7 \%)$ & 0.006 \\
\hline Abbrevital & $16(45.7 \%)$ & $20(83.3 \%)$ & \\
\hline
\end{tabular}

Abbreviations: SS, Shorter survival; LS, Longer survival.

Table 3. Univariate and multivariate analyses of the prognostic factors for osteosarcoma patients with metachronous metastatic relapse.

\begin{tabular}{|c|c|c|c|c|c|c|}
\hline Variables & HR & $\begin{array}{l}\text { Univariate } \\
95 \% \mathrm{CI}\end{array}$ & $\mathrm{P}$ & HR & $\begin{array}{l}\text { Multivariate } \\
95 \% \text { CI }\end{array}$ & $\mathrm{P}$ \\
\hline \multicolumn{7}{|l|}{ Gender } \\
\hline Male vs Female & 2.310 & $1.201-4.441$ & 0.012 & 2.192 & $0.744-6.457$ & 0.154 \\
\hline \multicolumn{7}{|l|}{ Age (years) } \\
\hline$\geq 15$ vs $<15$ & 0.718 & $0.381-1.354$ & 0.306 & & & \\
\hline \multicolumn{7}{|l|}{$\begin{array}{l}\text { Duration of symptoms } \\
\text { (months) }\end{array}$} \\
\hline$\geq 3$ vs $<3$ & 0.599 & $0.274-1.308$ & 0.198 & & & \\
\hline \multicolumn{7}{|l|}{ Size $(\mathrm{cm})$} \\
\hline$\geq 8$ vs $<8$ & 4.313 & $2.108-8.824$ & 0.000 & 3.491 & $1.282-9.510$ & 0.014 \\
\hline \multicolumn{7}{|l|}{ Histological grade } \\
\hline G1 vs G2 & 24.592 & $0.292-2070.210$ & 0.157 & & & \\
\hline \multicolumn{7}{|l|}{ Site of primary tumor } \\
\hline $\mathrm{T} 1$ vs $\mathrm{T} 2$ & 1.428 & $0.752-2.712$ & 0.276 & & & \\
\hline \multicolumn{7}{|l|}{ Enneking stage } \\
\hline IIB vs I-IIA & 2.309 & $1.206-4.418$ & 0.012 & 1.372 & $0.583-3.233$ & 0.469 \\
\hline \multicolumn{7}{|l|}{ Pathologic fracture } \\
\hline Yes vs No & 1.648 & $0.642-4.228$ & 0.299 & & & \\
\hline \multicolumn{7}{|l|}{ Anatomic location } \\
\hline Distal femur vs Others & 0.620 & $0.333-1.167$ & 0.139 & & & \\
\hline \multicolumn{7}{|l|}{ Pathological types } \\
\hline $\begin{array}{l}\text { Conventional vs } \\
\text { Nonconventional } \\
\text { Surgical methods }\end{array}$ & 3.651 & $0.875-15.237$ & 0.076 & & & \\
\hline $\begin{array}{l}\text { Amputation vs Limb } \\
\text { salvage }\end{array}$ & 0.569 & $0.301-1.077$ & 0.083 & & & \\
\hline \multicolumn{7}{|l|}{ Type of metastasis } \\
\hline $\begin{array}{l}\text { Solitary pulmonary vs } \\
\text { Multiple pulmonary or } \\
\text { other organs }\end{array}$ & 0.203 & $0.072-0.576$ & 0.003 & 0.269 & 0.091-0.799 & 0.018 \\
\hline \multicolumn{7}{|l|}{$\begin{array}{l}\text { Treatment after } \\
\text { metastasis }\end{array}$} \\
\hline $\begin{array}{l}\text { Curative vs Palliative } \\
\text { or no treatment }\end{array}$ & 0.364 & $0.192-0.691$ & 0.002 & 0.514 & $0.221-1.197$ & 0.123 \\
\hline \multicolumn{7}{|l|}{ ALP level at diagnosis } \\
\hline $\begin{array}{l}\text { Elevation vs Normal } \\
\text { LDH level at diagnosis }\end{array}$ & \multicolumn{5}{|c|}{ LDH level at diagnosis } & 0.000 \\
\hline $\begin{array}{l}\text { Elevation vs normal } \\
\text { ALP level after } \\
\text { metastasis }\end{array}$ & 1.996 & $0.969-4.109$ & 0.061 & & & \\
\hline $\begin{array}{l}\text { Elevation vs Normal } \\
\text { LDH level after } \\
\text { metastasis }\end{array}$ & 2.361 & $1.082-5.156$ & 0.031 & 1.222 & $0.326-4.584$ & 0.767 \\
\hline Elevation vs Normal & 3.378 & $1.747-6.533$ & 0.000 & 0.972 & $0.286-3.303$ & 0.963 \\
\hline
\end{tabular}




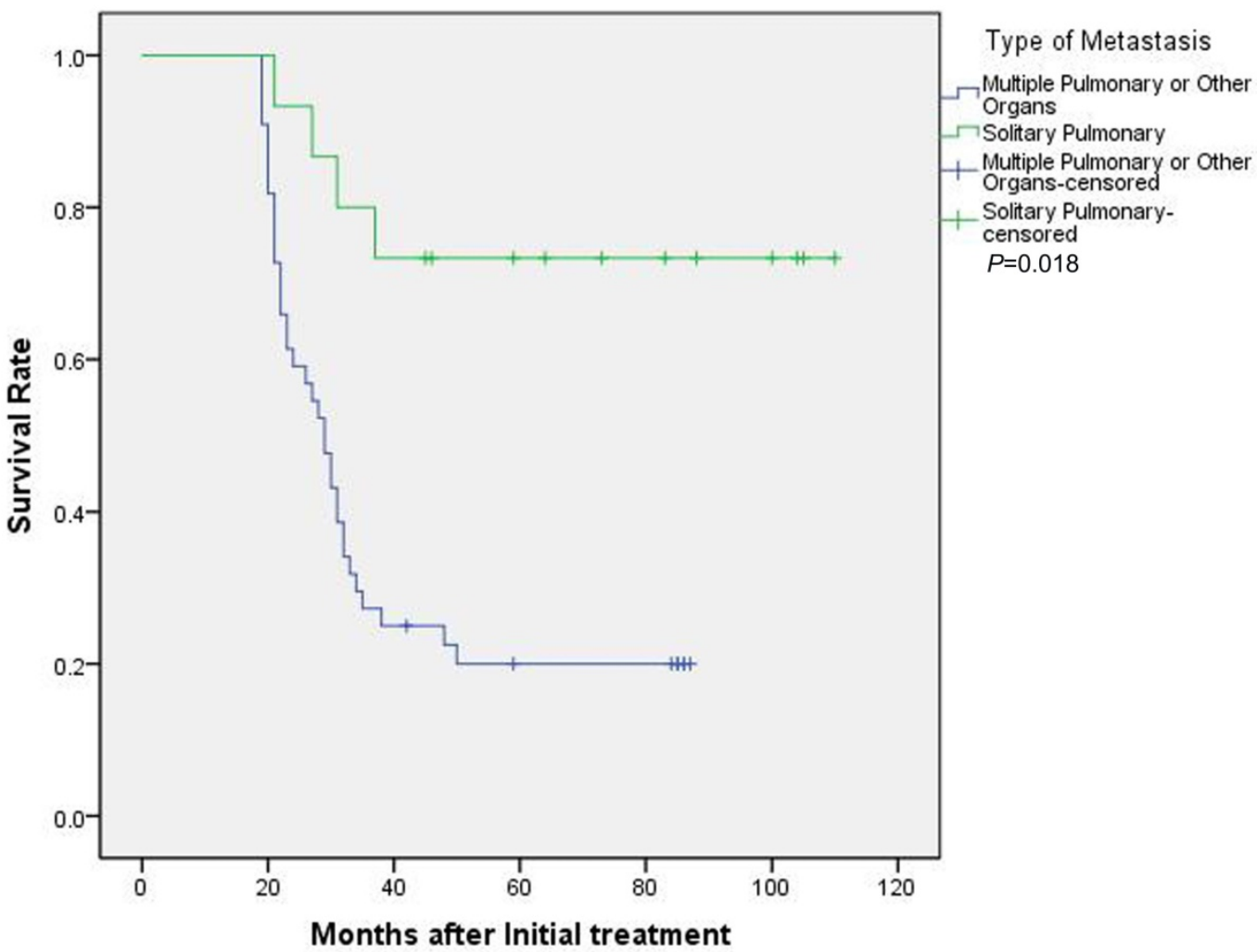

Figure 2. Kaplan-Meier survival curves of 59 metachronous metastatic osteosarcoma patients were stratified by type of metastasis. Significant differences in survival rate were observed between patients with solitary pulmonary and multiple pulmonary or other organs.

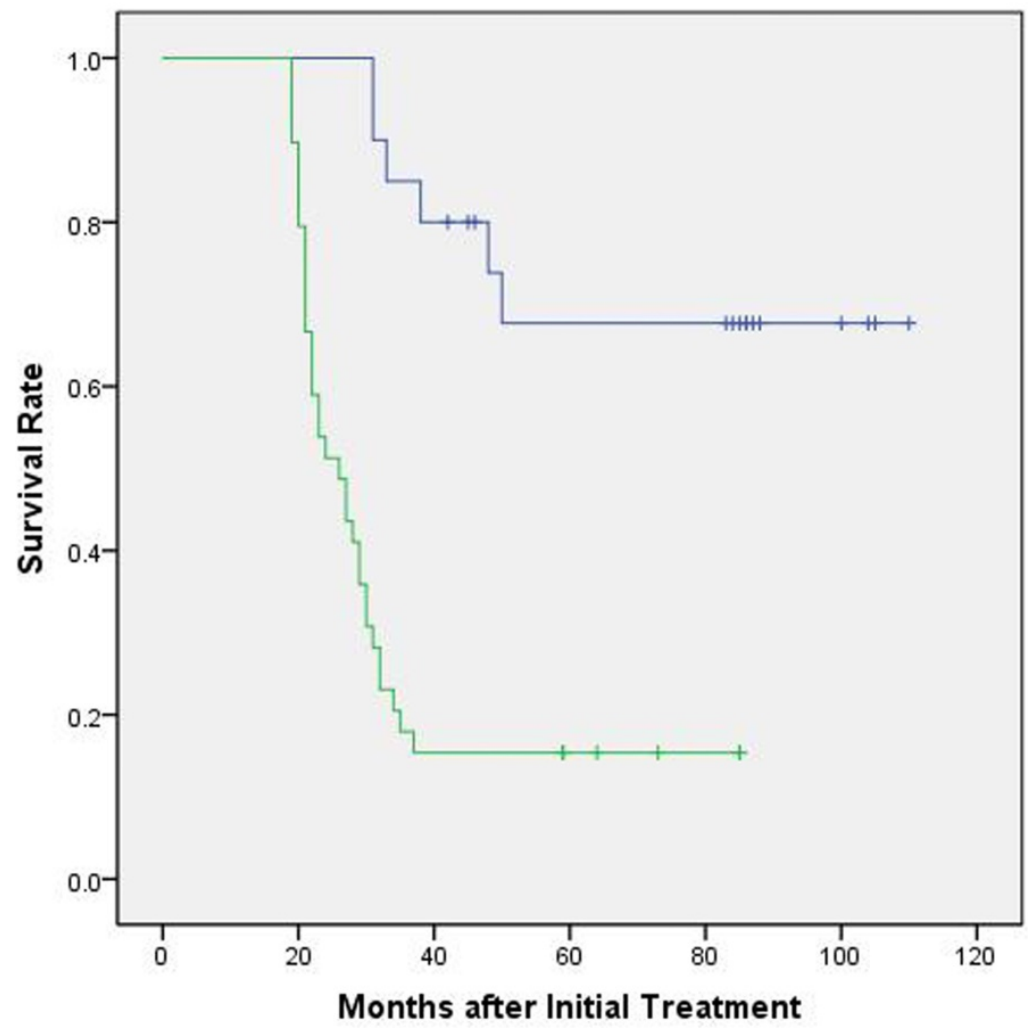

ALP Level at Dignosis

$\rightarrow$ Normal

- Elevated

+ Normal-censored

+ Elevated-censored

$P<0.001$

Months after Initial Treatment

Figure 3. Kaplan-Meier survival curves of 59 metachronous metastatic osteosarcoma patients were stratified by ALP level at diagnosis. Significant differences in survival rate were observed between patients with the elevated ALP at diagnosis and normal ALP. 


\section{Discussion}

Metachronous metastatic relapse is a major potential factor for the low survival of osteosarcoma patients who received both radical surgery and standardized chemotherapy [8]. In our present cohort, we included 59 cases of osteosarcoma patients with metachronous metastatic relapse. There were 43 deaths and the median OS was 31 months. Overall, the 2-, 3-, and 4-year survival rates were $69.5 \%, 40.7 \%$, and $30.5 \%$, respectively. For comparison, the mortality, median OS and survival rate of these patients were much lower than overall osteosarcoma patients, especially those patients without metastasis after radical surgery and standardized chemotherapy. Moreover, our analysis identified that the median OS of EM group (24 months) was significantly shorter than that of LM group (83 months), all these data indicated that the metachronous metastatic relapse was the main factor that seriously threatened the prognosis of patients with osteosarcoma.

Researches showed that osteosarcoma's metastasis mainly throughout the bloodstream [1,4, 9]. Lung is the organ of blood exchange, and it is also the common metastatic site of most tumors. In our cohort, the lung was the major involved metastatic organ, and $86.4 \%$ of patients occurred pulmonary metastasis. Patients with multiple pulmonary metastases had shorter survival and poor prognosis than patients with solitary pulmonary metastasis or other organ metastasis. Most of them have no obvious symptoms. During the follow-up, these patients were diagnosed as distant metastatic osteosarcoma. Therefore, patients should be followed regularly after their standard treatment to detect the metastatic tumor in the early stage. IL-6 and CXCL8 as primary mediators of OS lung tropism and suggest pleiotropic, redundant mechanisms by which they might affect metastasis [10]. Zhang Y and his colleagues found that down-regulation of Skp2 expression inhibits invasion and pulmonary metastasis in osteosarcoma [11]. Overexpression of ONZIN in human osteosarcoma patients was closely associated with pulmonary metastasis, poor prognosis, and survival [12]. In the future, pulmonary metastasis of osteosarcoma patients may be detected in the early stage based on cytokines or special markers and new molecular targeted therapy may be used for osteosarcoma patients with metastatic relapse.

In this study, the male/female ratio was 1.19:1. This may be because male patients are more prone to metastatic relapse. Furthermore, the male gender will accelerate the early metachronous metastatic relapse of osteosarcoma. The result was consistent with the previous study which showed that male patients usually have a worse prognosis than female in the overall osteosarcoma patients [13]. A study analyzed 333 high-grade osteosarcoma patients and found the female patients treated by multidisciplinary combined therapy were correlated with a better outcome than male patients [14]. Hyde $Z$ and colleagues found that higher free testosterone was associated with prostate cancer and lung cancer which are male high incidence of diseases [15]. An up-regulated release of the male hormone may be an important modulator for the metachronous metastatic relapse of osteosarcoma. Recent research has shown that tumor size was a significant prognostic indicator for cancer patients. Simultaneously, a paper found that large tumor size was a vital prognostic factor of widely invasive follicular thyroid carcinoma [16]. Also, tumor size was a reliable prognostic factor for patients with gastric cancer, and the measurement of tumor size would be beneficial to the staging and management of gastric cancer [17]. In a systematic revision of prognostic factors for osteosarcoma, it was found that the presence of metastasis, primary tumor size and site were important prognostic factors [18]. In our study, the median diameter of the tumor was larger than that in previous studies in overall osteosarcoma [4], 30/34 patients whose tumor size $\geq$ $8 \mathrm{~cm}$ were prone to early metastasis, $27 / 34$ patients had a short survival, and tumor size was also an independent prognostic factor for those patients. All these suggested that the prognosis of patients with tumor size $\geq 8 \mathrm{~cm}$ was extremely poor.

High-grade osteosarcomas are prone to distant metastases, and patients with the high-grade osteosarcoma have a poor prognosis [19]. Our research had come to the same conclusion. Anja Luetke summarized that patients with high-grade osteosarcoma also had poor sensitivity to radiation and chemotherapy [20]. Topkas E found that TXNRD2 may represent a novel druggable target that could be deployed to reduce the development of fatal pulmonary metastases in patients with OS [21]. Shimizu $\mathrm{T}$ and his colleagues found that immune checkpoint inhibitors may be an innovative therapy for lung metastases of advanced pediatric solid tumors [22]. In this study, patients who accepted curative treatment had better survival. Although the treatment regimen was not very uniform, and we cannot determine which treatment was more effective, it is necessary to give the appropriate treatment for metastatic osteosarcoma patients. In our survival analysis indicated that the Enneking stage was a prognostic indicator for osteosarcoma patients with metachronous metastatic relapse. Enneking stage is an important factor to guide surgical treatment and affect the survival of osteosarcoma 
patients [23]. Some researchers had shown that the prognosis of osteosarcoma patients was related to the Enneking stages and distant metastasis [24]. It is shown that the most common site of osteosarcoma is around the knee joint and the most common pathological types of osteosarcoma are conventional types. In our study, we had a similar conclusion that the primary lesion of $81.4 \%$ located nearby the knee joint of patients, and tumors located at the distal femur are more prone to distant metastasis. Our analysis showed that early metastasis was more likely to occur in conventional osteosarcoma patients. Conventional osteosarcoma is a highly malignant tumor, while other types such as parosteal osteosarcoma belong to a low-grade tumor and the malignant degree is closely correlated to distant metastasis in osteosarcoma patients $[1,4]$.

ALP is a classic enzyme associated with osteosarcoma. The bone-specific alkaline phosphatase (BALP) was analyzed to explore the role of ALP in osteosarcoma [25]. Researchers found that the serum BALP level was related to metastasis of osteosarcoma patients, and a continuously or progressively higher serum BALP level would be considered as aggressive investigation during follow-up. The increased level of ALP was also associated with distant metastasis after surgery in osteosarcoma patient [26]. Osteosarcoma patients with different level of ALP were analyzed to reveal the phenomenon that the risk of metastasis would increase when the level of ALP elevated [27]. The level of ALP is related to the prognosis of osteosarcoma patients $[28,29]$. In the meta-analysis, high serum ALP level was apparently related to poor survival rate and presence of metastasis at diagnosis [30]. Our data also suggested that high-level ALP in osteosarcoma patients may lead to early distant metastasis and short-survival. It was also an independent prognostic factor. LDH is an enzyme involved in cancer metabolism [25]. Higher serum $\mathrm{LDH}$ and the presence of metastatic tumor made a negative effect on the prognosis for osteosarcoma patients [31]. A meta-analysis revealed that higher serum LDH level was obviously related to worse overall survival probability in osteosarcoma patients, and it was an effective biomarker of prognosis [32]. In our analysis, higher LDH was associated with shorter survival after metastasis.

Osteosarcoma patients with these characteristics, such as tumor size $\geq 8 \mathrm{~cm}$, multiple pulmonary metastases, elevated ALP level at diagnosis that might be easy to develop to distant metastasis after standardized treatment and have a poor prognosis. These patients may be less sensitive to traditional treatment method. Therefore, whether we can explore specific treatment plans for such patients remains to be investigated in the future clinical treatment process.

Taking into the morbidity of osteosarcoma, the standard of treatment, and the limitations of the enrolled patients, this study only analyzed the clinicopathological features and prognostic factors of 59 cases of osteosarcoma patients with metachronous metastatic relapse. To seek potential mechanisms of metachronous metastatic relapse, especially the early metachronous metastatic relapse and take effective methods to prevent metastasis or delay the metastasis to improve the overall survival of osteosarcoma patients. Future studies should be conducted with multi-center cooperation for a wider range of retrospective or prospective studies to obtain a more reliable theoretical basis for the risk of metastasis and prognostic factors in osteosarcoma patients.

\section{Conclusion}

Osteosarcoma patients with metachronous metastatic relapse have some features that can be effective predictions for a possibility of early metastasis and the prognosis of the patients. Although the precise mechanisms of metachronous metastatic relapse remain poorly understood, the results of our study might promote to future investigate for osteosarcoma patients with metachronous metastatic relapse.

\section{Acknowledgments}

We sincerely thank our colleagues who participated in this research.

\section{Funding}

This study was funded by Hai Yan Funding (grant number JJ2D2017-08) and China Postdoctoral Science Foundation (grant number 2017M611393).

\section{Competing Interests}

The authors have declared that no competing interest exists.

\section{References}

1. Messerschmitt PJ, Garcia RM, Abdul-Karim FW, Greenfield EM Getty PJ: Osteosarcoma. J Am Acad Orthop Surg. 2009; 17 (8):515-527.

2. Bielack S, Carrle D, Casali PG, ESMO Guidelines Working Group: Osteosarcoma: ESMO clinical recommendations for diagnosis, treatment and follow-up. Ann Oncol. 2009; 20 Suppl 4:137-139.

3. Zhang W, Zhao JM, Lin J, Hu CZ, Zhang WB, Yang WL, Zhang J, Zhang JW, Zhu J: Adaptive Fibrogenic Reprogramming of Osteosarcoma Stem Cells Promotes Metastatic Growth. Cell Rep. 2018; 24 (5):1266-1277.

4. Moore DD, Luu HH. Osteosarcoma. Cancer Treat Res. 2014; 162:65-92.

5. Kansara M, Teng MW, Smyth MJ and Thomas DM. Translational biology of osteosarcoma. Nat Rev Cancer. 2014; 14 (11):722-735.

6. Li SW, Hu KZ, Chen SC, Liu SL, Wang YH. High expression of long non-coding RNA LOC730101 correlates with distant metastasis and exhibits a poor prognosis in patients with osteosarcoma. Eur Rev Med Pharmacol Sci. 2018; 22 (13):4115-4120.

7. Qin Y, Ye J, Zhao F, Hu S, Wang S. TRIM2 regulates the development and metastasis of tumorous cells of osteosarcoma. Int J Oncol. 2018; 53 (4):1643-1656. 
8. Salah S, Ahmad R, Sultan I, Yaser S, Shehadeh A. Osteosarcoma with metastasis at initial diagnosis: Current outcomes and prognostic factors in the context of a comprehensive cancer center. Molecular and clinical oncology. 2014; 2 (5):811-816.

9. O'Farrill JS, Gordon N. Autophagy in osteosarcoma. Adv Exp Med Biol. 2014; 804:147-160.

10. Gross AC, Cam H, Phelps DA, Saraf AJ, Bid HK, Cam M, London CA, Winget SA, Arnold MA, Brandolini L et al: IL-6 and CXCL8 mediate osteosarcoma-lung interactions critical to metastasis. JCI Insight. 2018; [Epub ahead of print]

11. Zhang Y, Zvi YS, Batko B, Zaphiros N, O'Donnell EF, Wang J, Sato K, Yang R, Geller DS, Koirala $P$ et al: Down-regulation of Skp2 expression inhibits invasion and lung metastasis in osteosarcoma. Sci Rep. 2018; 8 (1):14294.

12. Zhang Y, Hu O, Li G, Li L, Liang S, Zhang Y, Liu J, Fan Z, Li L, Zhou B et al: ONZIN Upregulation by Mutant p53 Contributes to OsteosarcomaMetastasis Through the CXCL5-MAPK Signaling Pathway. Cell Physiol Biochem. 2018; 48 (3):1099-1111.

13. Xing D, Qasem SA, Owusu K, Zhang K, Siegal GP, Wei S: Changing prognostic factors in osteosarcoma: analysis of 381 cases from two institutions. Hum Pathol. 2014; 45 (8):1688-1696.

14. Min D, Lin F, Shen Z, Zheng S, Tan L, Yu W, Yao Y: Analysis of prognostic factors in 333 Chinese patients with high-grade osteosarcoma treated by multidisciplinary combined therapy. Asia Pac J Clin Oncol. 2013; 9 (1):71-79.

15. Hyde Z, Flicker L, McCaul KA, Almeida OP, Hankey GJ, Chubb SA, Yeap BB: Associations between testosterone levels and incident prostate, lung, and colorectal cancer. A population-based study. Cancer Epidemiol Biomarkers Prev. 2012; 21 (8):1319-1329.

16. Ito $\mathrm{Y}$, Hirokawa $\mathrm{M}$, Masuoka $\mathrm{H}$, Yabuta $\mathrm{T}$, Fukushima $\mathrm{M}$, Kihara $\mathrm{M}$, Higashiyama T, Takamura Y,Kobayashi K, Miya A et al: Distant metastasis at diagnosis and large tumor size are significant prognostic factors of widely invasive follicular thyroid carcinoma. Endocr J. 2013; 60 (6):829-833.

17. Guo P, Li Y, Zhu Z, Sun Z, Lu C, Wang Z, Xu H: Prognostic value of tumor size in gastric cancer: an analysis of 2,379 patients. Tumour Biol. 2013; 34 (2):1027-1035.

18. Bramer JA, van Linge JH, Grimer RJ, Scholten RJ. Prognostic factors in localized extremity osteosarcoma: a systematic review. Eur J Surg Oncol. 2009; 35 (10):1030-1036

19. van Oosterwijk JG, Anninga JK, Gelderblom H, Cleton-Jansen AM, Bovée JV: Update on targets and novel treatment options for high-grade osteosarcoma and chondrosarcoma. Hematol Oncol Clin North Am. 2013; 27 (5):1021-1048.

20. Luetke A, Meyers PA, Lewis I, Juergens H: Osteosarcoma treatment - where do we stand? A state of the art review. Cancer Treat Rev. 2014; 40 (4):523-532.

21. Topkas E, Cai N, Cumming A, Hazar-Rethinam M, Gannon OM, Burgess M, Saunders NA, Endo-Munoz L: Auranofin is a potent suppressor of osteosarcoma metastasis. Oncotarget. 2016; 7 (1):831-844.

22. Shimizu T, Fuchimoto Y, Fukuda K, Okita H, Kitagawa Y, Kuroda T: The effect of immune checkpoint inhibitors on lung metastases of osteosarcoma. J Pediatr Surg. 2017; 52 (12):2047-2050.

23. Fu Y, Lan T, Cai $\mathrm{H}, \mathrm{Lu} \mathrm{A}, \mathrm{Yu} \mathrm{W}$ : Meta-analysis of serum lactate dehydrogenase and prognosis for osteosarcoma. Medicine (Baltimore). 2018; 97 (19):e0741.

24. Kim SH, Shin KH, Kim HY, Cho YJ, Noh JK, Suh JS, Yang WI: Postoperative nomogram to predict the probability of metastasis in Enneking stage IIB extremity osteosarcoma. BMC Cancer. 2014; 14:666.

25. Limmahakhun $\mathrm{S}$, Pothacharoen $\mathrm{P}$, Theera-Umpon $\mathrm{N}$, Arpornchayanon $\mathrm{O}$ Leerapun T, Luevitoonvechkij S, Pruksakorn D: Relationships between serum biomarker levels and clinical presentation of human osteosarcomas. Asian Pac J Cancer Prev. 2011; 12 (7):1717-1722.

26. Hsieh MY, Hung GY, Yen HI, Chen WM, Chen TH: Osteosarcoma in preadolescent patients: experience in a single institute in Taiwan. J Chin Med Assoc. 2009; 72 (9):455-461.

27. Han J, Yong B, Luo C, Tan P, Peng T, Shen J: High serum alkaline phosphatase cooperating with MMP-9 predicts metastasis and poor prognosis in patients with primary osteosarcoma in Southern China. World J Surg Oncol. 2012; 10:37.

28. Bielack SS, Kempf-Bielack B, Delling G, Exner GU, Flege S, Helmke K, Kotz R, Salzer-Kuntschik M,Werner M, Winkelmann W et al: Prognostic factors in high-grade osteosarcoma of the extremities or trunk: an analysis of 1,702 patients treated on neoadjuvant cooperative osteosarcoma study group protocols. J Clin Oncol. 2002; 20 (3):776-790.

29. Ambroszkiewicz J, Gajewska J, Klepacka T, Chelchowska M, Laskowska-Klita T, Wozniak W: Clinical utility of biochemical bone turnover markers in children and adolescents with osteosarcoma. Adv Med Sci. 2010; 55 (2):266-272.

30. Ren HY, Sun LL, Li HY, Ye ZM. Prognostic Significance of Serum Alkaline Phosphatase Level in Osteosarcoma: A Meta-Analysis of Published Data. Biomed Res Int. 2015; 2015:160835.

31. Rech A, Castro CG Jr, Mattei J, Gregianin L, Di Leone L, David A, Rivero LF, Tarrago R, Abreu A, Brunetto AL. [Clinical features in osteosarcoma and prognostic implications]. J Pediatr (Rio J). 2004; 80 (1):65-70.

32. Chen J, Sun MX, Hua YQ, Cai ZD. Prognostic significance of serum lactate dehydrogenase level in osteosarcoma: a meta-analysis. J Cancer Res Clin Oncol. 2014; 140 (7):1205-1210. 